\title{
Interculturalismo y Cooperativismo
}

\author{
Siegbert Rippe \\ Catedrático de Derecho Comercial \\ (Universidad de la República de Uruguay)
}

\section{Introducción}

Nos proponemos en la oportunidad $-\mathrm{y}$ en el marco de la invitación recibida para colaborar en la investigación propuesta sobre el tema de referencia - resaltar algunos «hallazgos» que se presentaron en el desarrollo de este trabajo y aportar, aún en su modestia, algunas impresiones, incluso eventuales opiniones personales al respecto.

Para iniciar el tratamiento del mencionado tema entendemos oportuno formular algunas previas precisiones conceptuales con relación al interculturalismo mismo, para luego introducirnos en un breve análisis del cooperativismo en nuestro país, lo que nos permitirá aproximarnos a determinar las relaciones que se dan -y más aún, podrían darse e incluso promoverse - entre este movimiento socioeconómico y la cultura —en su sentido más amplio y omni comprensivo- en sus distintas manifestaciones. Veamos por su orden.

La Cultura, entendida ésta como el conjunto total de los actos creados por el ser humano en una comunidad dada, ya sean éstas prácticas tales como: económicas, políticas, científicas, jurídicas, religiosas, discursivas, comunicativas o sociales, resulta orientadora de la acción de los individuos y grupos sociales ${ }^{1}$.

1 Huntingron, Samuel P.; HARRISON, Lawrence E.: «La cultura es lo que importa», ed. Planeta, pp. 38 y 39 (2001), Argentina. 
Si bien aquella cambia dinámica y constantemente, por los propios cambios que suceden en la sociedad, los mismos se intensificaron a fines del siglo pasado y en lo que va de éste, ya que la globalización, seguida de los avances tecnológicos, es parte de los asuntos cotidianos de todas las sociedades, y por ende de sus culturas².

Ahora bien. No es, no existe una única, unitaria cultura. En efecto. La cultura, su práctica, sus alteraciones y hasta su misma permanencia en el tiempo se debe a su gestación en el interior de los diversos grupos. Los seres humanos, agrupados de acuerdo a las afinidades que los unen (ideológicas, de clase, de credo, de origen territorial, de origen étnico, de edad, de sexo, etc.), generan y comparten modos de ser y hasta un lenguaje propio que son parte de su propia, singular cultura, esto es, de su subcultura. La interrelación entre las diversas culturas, o subculturas, que coexisten en cualquier país es una relación entre personas, entre instituciones y entre grupos sociales. Por ende, cuanto más estratificado sea socialmente un país o hasta una ciudad, más compleja será la interrelación entre las subculturas que en su conjunto hacen a la cultura de un país ${ }^{3}$, y que los individuos incorporan a través de los diferentes medios de socialización (la familia, la escuela, la comunidad, el medio laboral y las instituciones, contextos sociales éstos en los que incluimos, obviamente, a las cooperativas).

Esta pluriculturalidad o multiculturalidad, como suele llamársele, cuando entra en contacto con otras culturas (suma de varias subculturas igualmente), conforma la denominada interculturalidad, la que será tanto más intensa cuanto mayor sea el grado de comunicación que permita un más elevado nivel de conocimiento del otro llegando, incluso, a la incorporación de hábitos propios de éste. Esto es lo que se conoce como interculturalidad real ${ }^{4}$.

La diversidad cultural, existente en cada país bajo la genérica denominación de "cultura», se interrelaciona con las otras a nivel mundial y la interrelación entre todas es causa de los cambios culturales que se dan en las diferentes sociedades, sin perjuicio de la coexistencia, de mantener su propia identidad en los aspectos más esenciales. Por ello, tenemos entendido que un gran número de países (España,

2 SARLO, Beatriz: «Escenas de la vida Posmoderna», pp. 80 y 81, ed. Ariel, X edición (1998), Argentina.

3 www.blues.uab.es

${ }^{4}$ www.aulaintercultural.org 
Estados Unidos, Italia, entre otros), disponen de importantes y específicos recursos para difundir el prestigio y promover el desarrollo de las diversas culturas y subculturas 5 .

Este principio de interculturalidad, unido al desarrollo de la comunicación (entre organismos, países y sociedades) y al fomento económico y de aceptación de todas las culturas, lleva incluso al nacimiento de las llamadas «Cooperativas Culturales», que tienen por vocación, finalidad y objeto de su quehacer impulsar, fomentar, instrumentar y concretar, justamente, la fenomenología de la interculturalidad, en el marco socio-formal de su tipología cooperativa.

\section{Las cooperativas en el Uruguay}

Desde el punto de vista funcional, y de acuerdo a las resultancias del «Primer Relevamiento Nacional de Entidades Cooperativas», sería posible sostener que este movimiento atraviesa la mayor parte de las clases sociales, con excepción, tal vez, de la más alta, en términos de su status social y económico, por lo pronto, en algunas de sus modalidades o sectores de actividad, con un policlasismo con predominio de los niveles medios y medios bajos de la población, con tendencia a defender la calidad de vida de los cooperativistas ante un proceso de deterioro general, con una proporción de integrantes con buenos niveles de estudios, y clara prevalencia de los hombres, siendo, salvo excepciones sectoriales, relativamente escasa la intervención femenina. Hasta entonces (1989-92) no sólo no se observaba presencia de capital extranjero sino que, más aún, el movimiento captó un capital nacional que no sale de fronteras ${ }^{6}$.

Desde nuestro punto de vista, coincidiríamos con los investigadores abajo citados, en que se daba el aprovechamiento de la acción colectiva para definir individualmente la propia y mejor oportunidad, conocida como la vocación por el free rider ${ }^{7}$ a que aludía Olson, en cita de aquellos. Dicho lo anterior, queda explicado el normal incremento

5 www.cidob.ec

6 ERrandonea, Alfredo y Supervielle, Marcos (1992): Las Cooperativas en el Uruguay. Análisis Sociológico del Primer Relevamiento Nacional de Entidades Cooperativas, pp. 58 y 59, Montevideo, FCU.

7 ERrandonea, Alfredo y Supervielle, Marcos: ob. cit., p. 89. 
de asociados en las cooperativas, su baja participación en la vida cotidiana de ellas y la baja solidaridad de los socios con la entidad, que se combina con una fuerte presencia del modelo cooperativo frente a las dificultades económicas que se venían dando en aquellas fechas.

Con relación al proceso histórico, es oportuno recordar que desde finales del siglo XIX hasta mediados de los años 1950, el estado proteccionista, el llamado en su momento «Estado de Bienestar», asumió un papel protagónico en el desarrollo social con medidas que facilitaron asimismo el desarrollo del propio cooperativismo, y pese a que posteriormente hubo políticas públicas que no consideraron o hasta se desentendieron de ciertas problemáticas sociales y económicas antes estatalmente contempladas o atendidas - y dejaron así espacios o nichos consecuentemente sin atender - o estos fueron aprovechados oportunamente por el cooperativismo, a pesar de ciertos periodos de franca resistencia político-estatal al movimiento cooperativo. Dicho en otros términos, el cooperativismo pasa a ocupar los espacios que el estado batllista de bienestar, prevalente en la primera mitad del siglo $\mathrm{xx}$, deja en su transformación y se constituye en un medio para enfrentar la inestabilidad de futuro ${ }^{8}$.

\section{¿Pero que entendemos por Cooperativa a los efectos del presente trabajo?}

Es «la organización económica que asocia a las personas que, vinculadas por necesidades comunes, se unen para desarrollar en común actividades destinadas a satisfacerlas en su propio, individual beneficio» ${ }^{9}$.

En cuanto a los aspectos legales de las cooperativas, en términos generales digamos que:

- No existe todavía - aunque ello está actualmente en proceso parlamentario - un texto legal que regule total y unitariamente la fenomenología cooperativa y la globalidad de los tipos cooperativos sino que, por el contrario, cada uno de ellos se rige todavía por un régimen legal específico y diferencial, esto es,

8 Errandonea, Alfredo y Supervielle, Marcos: ob. cit., p. 90.

9 RIPPE, Siegbert: «Régimen legal de las Sociedades Cooperativas en el Derecho Uruguayo», 2. ${ }^{a}$ edición, Fundación de Cultura Uruguaya (1976). 
una ley singular, distinta y no extrapolable en sus soluciones, aunque siempre estructurada dentro de los fundamentos y principios del cooperativismo; Existe por ello una limitación legal en tanto la ley se restringe en su alcance al específico tipo cooperativo de que trata la misma y en tal contexto no podría haber en teoría, y hasta en la práctica, ninguna cooperativa con objeto o actividades sociales múltiples, con independencia de sus objetivos o finalidades últimas ${ }^{10}$.

- Según la época en que se sanciona una ley que crea un tipo cooperativo en concreto, varía la naturaleza jurídica que se le atribuye por parte del legislador, eventualmente por la doctrina académica, judicial, administrativa, profesional o simplemente gremial (comerciales en algunos casos, civiles en otros, tipificados en función de su naturaleza especial o con base en el acto cooperativo, entre otros).

- Es relativo y hasta cuestionable el control estatal.

- Se presentan dificultades o limitaciones normativas sobre organización, administración y gestión de la cooperativa.

- Se plantea una regulación incompleta de disposiciones sobre integración y educación.

- En los últimos años y hasta muy recientemente, se observa limitado interés estatal en el fomento orgánico y estructural del cooperativismo.

\section{Las sociedades civiles: una fuerte competencia}

Aún cuando el presente aporte se vincula con la idea del cooperativismo y con las cooperativas como instrumentos de realización del ideario cooperativo y sus relaciones reales o potenciales con el fenómeno de la interculturalidad, no es posible soslayar el hecho de que esa interculturalidad puede también realizarse $-\mathrm{y}$ naturalmente lograrse- a través de otros instrumentos o mecanismos formales e informales, y entre los mismos se encuentran las sociedades civiles, entendidas estas al solo efecto del presente trabajo, no tanto en función

10 Cooperativas de Consumo. Cooperativas de Ahorro y Crédito. Cooperativas de Producción, o de Trabajo Asociado. Cooperativas de Vivienda. Cooperativas Agrarias. Cooperativas Agroindustriales. Cooperativas Sociales. Cooperativas Escolares (sin legislación específica). 
de las sociedades que tienen forma u objeto o actividad civil, por contraposición a aquellas que por su forma o por su objeto o actividad son sociedades comerciales y, como éstas, tienen fines de lucro (persecución de ganancias y distribución de las mismas entre sus socios), sino respecto de aquellas que no tienen tales fines de lucro sino de otros tipos o características (sociales, culturales, etc.). Entre estas últimas cabe señalar las asociaciones y las fundaciones.

En efecto. El art. 21 del Código Civil de Uruguay, consagra la existencia de personas jurídicas como sujetos de derecho, desarrollándose la legislación en torno de las asociaciones civiles (grupos de personas reunidas por un interés común, que con la integración de un patrimonio buscan dar cumplimiento al objetivo deseado, solicitando el reconocimiento de la nueva entidad como independiente de sus integrantes). Su constitución no exige demasiados trámites (acta notarial, inscripción en el Registro de Personas Jurídicas, aprobación o más bien reconocimiento estatal de la personería, expedición de libros de actas y contable) y su costo es muy accesible. Además los controles son relativamente laxos y pocos regulares.

Hasta el año en que entra en vigencia la Ley 17.163 (1999) las fundaciones (asignación de un patrimonio para cumplir determinados objetivos sin fines de lucro, en torno al cual se designan las personas que la administrarán), no eran reguladas por la legislación y con base al viejo aforismo, recogido en la Constitución Nacional (art. 10), que lo que no está prohibido está permitido, fueron generalmente admitidas, aún, incluso, hasta a veces y en ciertas épocas, con menos requisitos para su constitución que en el caso de las asociaciones civiles, sin perjuicio de advertirse una cierta, pública dubitabilidad y desconfianza sobre el objeto y alcance de su actuación, en cuanto se estima o existe la creencia de que son formas sociales también idóneas para la eventual comisión de actos en fraude a la ley. Actualmente, por la ley mencionada, deben cumplir las fundaciones con determinadas exigencias (órganos, votaciones, integración del capital, cuotas sociales, destino de los bienes sociales en caso de cese o de revocación de la personería, a título de ejemplo). El costo de la constitución es mínimo y los controles también.

Estas organizaciones asociativas, dentro de las cuales suelen quedar incluidas la ONGs, generalmente destinadas a fines sociales y culturales, tienen una vasta red de contactos a nivel nacional, regional y mundial con asociaciones y agrupaciones de derecho público y pri- 
vado que incluso prestan apoyo económico, cubriendo vastas áreas del conocimiento a través de una importante comunicación intercultural ${ }^{11}$.

Es observable que esas formas de organización asociativa tienen aptitud primaria suficiente para diseñar, instrumentar y ejecutar en la vida real, en la realidad cotidiana viviente, políticas y acciones culturales e interculturales, por lo que las cooperativas constituyen una forma o modalidad asociativa alternativa para tales objetivos o fines, con base en valores, principios y estructuras administrativas y funcionales propias y distintivas de las correspondientes a aquellas otras formas sociales.

\section{La interculturalidad y el cooperativismo: un desafío}

\section{A) El caso uruguayo}

Es preciso destacar, a modo de preámbulo de la presente sección de nuestra investigación, que no se ha podido detectar, o por lo pronto no ha resultado posible, notorio ni accesible la identificación de entidades cooperativas integradas por personas provenientes o pertenecientes a diferentes extractos subculturales que de manera consciente y voluntaria se hayan propuesto - sea porque esa fuera la razón de ser, el objetivo o finalidad de la cooperativa misma, sea porque esa fuera la intención y decisión de sus fundadores o componentes- promover o efectivizar, mediante el instrumental del cooperativismo, sus mecanismos y herramientas caracterizantes, fenómenos de interculturalidad en el seno de una cooperativa formal.

Podría coadyuvar al entendimiento de tal circunstancia el hecho de que en el Uruguay, en términos generales, no existe una población originariamente autóctona, su población es o ha sido producto de inmigraciones particularmente europeas de larga data, algunas de las cuales incluso introdujeron las ideas y prácticas cooperativas vigentes en sus países de origen, es un país en el que no se observan impactos propios de corrientes migratorias significativas provenientes de culturas o subculturas sustancialmente diferentes a las propias, y aunque

11 Por ejemplo: Asociaciones para el fomento de becas e intercambios educativos, organizaciones antidiscriminatorias, etc. 
existen núcleos poblacionales relativa y puntualmente identificables por sus diversos y específicos orígenes geo políticos, razas, creencias o religiones, estos suelen convivir armónica y respetuosamente en una sociedad caracterizada en general por su sensibilidad contraria a toda discriminación y por su tradicional, consecuente capacidad de entendimiento, integración y tolerancia multicultural.

Y aunque consta la existencia de experiencias formales y organizativas que promueven tal entendimiento, integración y tolerancia a través de mecanismos asociativos o convencionales, éstos hasta donde ha sido posible aprehender, no han adoptado en cambio el formato cooperativo, por lo que los ejemplos o las vivencias que se señalarán responden a un tipo cooperativo, tal vez atípico, de interculturalismo a considerar en la oportunidad.

En nuestro país podemos decir que se advirtió una cierta modalidad de proceso de interculturalidad cuando en junio de 1988 se crea y formaliza - sin perjuicio de la previa existencia de esquemas de integración de diversa, relativa formalidad- una Confederación con el fin de: velar por el cumplimiento de los principios cooperativos; fomentar el desarrollo del movimiento; asesorar al gobierno en la fijación de la política nacional; brindar asistencia técnica a las cooperativas; promover el intercambio de conocimientos y servicios, etc. Así nace la Confederación Uruguaya de Entidades Cooperativas (CUDECOOP).

Además, en 1992 se funda SURCO, una empresa de seguros integrada por cooperativas de segundo grado. Las cooperativas que se desarrollaban exitosamente en Uruguay, llevaron a que en fecha posterior también se cree el Fondo Nacional Cooperativo de Garantías (FOGAR), que es un Fondo que tuvo por objeto prestar servicios de garantías para acceder a créditos a cooperativas de cualquier modalidad, así como una Administradora de Fondos de Ahorro Previsional constituida por cooperativas (AFAP Integración), aunque a diferencia de los casos anteriores, tuvo que adoptar por imperio legal la forma de una sociedad anónima.

Entonces, desde 1988, con la fundación de CUDECOOP, en Uruguay se desarrolla el principio del intercooperativismo a través de un regulador institucional y privado que, motivado por el ideario del cooperativismo y conformado por el propio movimiento cooperativo organizado, busca promover los vínculos entre diferentes modalidades cooperativas. En efecto. 
La Comisión de Género. En 1990 se creó este plan que desarrolla actividades con el fin de que la mujer tenga una mayor participación, en condiciones de igualdad en todos los niveles de la red cooperativa nacional. Estos encuentros han sido implementados tanto a nivel local como internacional. Esta es una forma de fomentar que haya un intercooperativismo que tenga como objetivo promover la igualdad de género (o sea, un tema cultural) ${ }^{12}$.

La Comisión de Cooperativismo y Medio Ambiente, que funciona desde 1994, también vincula las cooperativas y su interrelación por un tema que es parte de la cultura de las diversas sociedades: el cuidado del medio ambiente. Dentro de esta comisión estuvo el «Proyecto de Incorporación de la Dimensión Ambiental en la Gestión de las Organizaciones Cooperativas Uruguayas-Proyecto SUMA (Cooperativismo + Ambiente)» que contó con el apoyo de la Comisión Europea y del Centro Cooperativo Sueco ${ }^{13}$.

Además, CUDECOOP promociona los Espacios Horizontales Locales (EHLS), orientados a favorecer el desarrollo de experiencias de intercambio y de colaboración entre las organizaciones cooperativas de diferentes sectores de actividad, para mejorar y fomentar el vínculo entre las cooperativas y su unidad como representación a nivel nacional. Busca en definitiva que haya un intercooperativismo a nivel local para un desarrollo más eficaz y sustentable.

En el año 1993 se realizó una Exposición de Productos y Servicios Cooperativos (EXPOCOOP 93), que tuvo como fin enseñar tanto las oportunidades como el potencial del cooperativismo en Uruguay, y obtuvo significativa repercusión tanto a nivel nacional como internacional ${ }^{14}$.

Neticoop es otro de los programas desarrollado y sustentado por CUDECOOP. Este programa tiene como fin promover el uso de las nuevas tecnologías en las cooperativas. Este programa fomenta el desarrollo de las cooperativas a través de la cultura informática, creando no sólo una mayor relación entre las cooperativas sino que también potenciando los vínculos con la globalización mediática ${ }^{15}$.

12 www.cudecoop.org.uy

13 www.cudecoop.org.uy

14 CUDECOOP: «Catálogo del Cooperativismo Uruguayo», ed. GEGA (1993).

15 www.cudecoop.org.uy 
En este relevamiento resumido de esfuerzos realizados en el ámbito del quehacer cooperativo no puede dejarse de mencionar la creación y funcionamiento de una unidad público-estatal orientada a la promoción del sistema cooperativo, como es la Comisión Honoraria de Cooperativismo, integrada por representantes del Poder Ejecutivo Nacional y del movimiento cooperativo organizado en CUDECOOP.

Como se destacó anteriormente las cooperativas pueden tener, además de sus objetivos económicos, objetivos sociales y culturales:

«Social» quiere decir la satisfacción de sus objetivos sociales, tal como la provisión de servicios de salud o guardería. Tales actividades deben ser conducidas de una manera económica para que provean el tipo de servicio que beneficia a los miembros. Las cooperativas también pueden abarcar metas «culturales» de acuerdo a los intereses y deseos de los miembros: por ejemplo, asistir en la promoción de una cultura nacional, promoviendo la paz, patrocinando deportes y actividades culturales, y mejorando las relaciones de la comunidad. En verdad, en el futuro, ayudando a proveer una mejor manera de vivir - cultural, intelectual y espiritual_ puede convertirse en una de las maneras más importantes por la cual las cooperativas pueden beneficiar a sus miembros y contribuir con sus comunidades» ${ }^{16}$.

En las cooperativas en general, los seres humanos expresan su sociabilidad, pero además en las cooperativas culturales en particular, se potencian sus capacidades, formas de vida y comportamiento, así como su inserción en la sociedad en general. La diversidad de las cooperativas varía según cada país, región y/o sociedad. Consta que en el mundo entero, o por lo menos en muchas de sus partes, existen, por ejemplo, cooperativas que se constituyen y operan para el fortalecimiento de los derechos de las mujeres, hasta cooperativas donde prevalece una forma de expresión artística ${ }^{17}$.

Las relaciones culturales son el fundamento de muchas organizaciones y cooperativas. Las cooperativas culturales en el siglo XXI, son un lugar donde se articulan procesos y actividades que involucran a cada vez más personas en espacios que superan el espacio local,

16 CUdECOOP (Editorial Norman) Comunidad: «Identidad y Principios Cooperativos», p. 23, Ed. Comunidad del Sur (1996).

17 www.unircoop.org 
creando tejidos de interacción y complementariedad con otras culturas. Por ello, las cooperativas culturales pasan a ser protagonistas de los proceso de interculturalidad y multiculturalidad que se están llevando a cabo en el mundo entero.

En el actual panorama de la globalización, las cooperativas, que antes evolucionaban en una dinámica local centrada en segmentos sociales específicos, han debido ajustarse actualmente a los cambios y promover el intercambio de experiencias, actividades y doctrinas con otras cooperativas. Este intercambio fomenta la interculturalidad y el desarrollo de las cooperativas, siendo éstas cada vez más protagonistas de la sociedad y la economía de los países. Las cooperativas están rigiéndose por un Modelo de Intercooperación que conjugue la personalidad local de las mismas con otras cooperativas de forma dinámica, sinérgica y permanente ${ }^{18}$.

En el Día Internacional de las Cooperativas, celebrado el 1 de julio de 2006 la celebración con la consigna «construir la paz a través de las cooperativas» muestra el interés mundial por las cooperativas, de ser parte protagonista de la unión de las diferentes culturas a través de un fin común. Frente a este día Internacional CUDECOOP afianzó su esfuerzo por promover el desarrollo de las cooperativas como una forma de luchar por la inclusión de la productividad y solidaridad en el Uruguay $^{19}$.

Un ejemplo de la intercooperación que fomenta la interculturalidad es el trabajo en conjunto entre las universidades y las cooperativas, que se manifiesta en la existencia de programas de apoyo académico, investigativo y de asistencia técnica. Bajo este concepto se creó la Red Universitaria de las Américas (de la cual Uruguay es uno de sus miembros), que ha facilitado el desarrollo del conocimiento y formación desde una perspectiva local/continental, impulsando a las cooperativas a dominar nuevas capacidades que le ayuden a asegurar el éxito en su trabajo social y económico en el medio en el que se desenvuelven ${ }^{20}$.

En suma, el Cooperativismo-Multiculturalismo es un movimiento que se está desenvolviendo en función de la multiplicidad de culturas

18 www.unircoop.org

19 wWw.cudecoop.org.uy

20 www.unircoop.org 
que, aunque ya existen desde hace muchos siglos, están desarrollando vínculos más estrechos gracias, entre otros factores, a los avances tecnológicos en las telecomunicaciones ${ }^{21}$.

La relación entre el multiculturalismo y el desarrollo cooperativo es o debería ser parte de las políticas estatales, ya que son la sinergia entre la aceptación de los derechos de todas las culturas y subculturas con el fin de promover la economía y la política social. Incluso las cooperativas culturales son el eje de acercamiento entre pueblos, culturas y países, una apreciación que conlleva a insistir separada y seguidamente sobre el particular, con mención, a título de presentación, de algunas experiencias al respecto.

\section{B) Las cooperativas culturales}

Las cooperativas uruguayas, pese a no caracterizarse por ser estrictamente culturales, sí incentivan, en cambio, acciones vinculadas a la sociedad y la cultura a través de patrocinios, mecenazgos, auspicios, publicidades, promociones y sponsoreo. Además, en muchas oportunidades, fomentan actividades que unifiquen a la sociedad y sus diferentes culturas ${ }^{22}$.

En Uruguay, las cooperativas constituyen una posibilidad de desarrollo tanto económico como intercultural ya que con la participación conjunta entre las mismas y diversos agentes locales, pueden, o por lo menos tendrían aptitud para aprovechar las ventajas de la globalización de forma comunitaria. En efecto. Las cooperativas culturales pueden ser ejes del proceso de socialización entre los individuos, más allá de las diferencias y similitudes culturales, por lo que se dirá seguidamente:

Las cooperativas son tipos de organizaciones que juntan, conjuntan a los individuos con un fin común. Esto es parte del proceso de socialización, siendo entonces las cooperativas parte de un proceso de identidad y de generación de valores, así como de potencialización de rasgos culturales. Las cooperativas pueden desarrollar acciones que

21 CASTELLS, Manuel: «Letra Internacional», artículo La sociedad red (verano de 2001).

22 Un ejemplo a citar es el evento artístico por la campaña: «¿Vos discriminas?», al que se sumó CUDECOOP el 24 de junio de 2006. 
impliquen el desarrollo de diversas culturas, uniendo esfuerzos y subculturas. Todas las cooperativas, más allá de sus fines económicos, de sus motivos de creación, de sus reglas o pautas de actuación, pueden ser incentivadas a desarrollar actividades que fomenten los pluriculturalismos.

CUDECOOP, en función de seguir los cometidos de las cooperativas, ha desarrollado varias áreas de trabajo donde fomenta en cierta forma, y hasta podría lograr, el interculturalismo dentro de las cooperativas.

Además, Uruguay, como país miembro del MERCOSUR (Mercado Común del Sur), es parte de la política de intercooperativismo de este proceso plurinacional e institucional de integración subregional. El MERCOSUR ha tenido en cuenta la importancia de los vínculos entre las cooperativas y por ello, a título de ejemplo, se realizó una Reunión Especializada de Cooperativas, oportunidad en la que se estableció el objetivo de crear un Foro destinado al análisis y al desarrollo de las cooperativas en el ámbito del espacio geopolítico integrado. La finalidad de esta reunión fue justamente la de «analizar y desarrollar proyectos en esta área, especialmente en lo referente a la armonización de aspectos legislativos; la complementación de actividades productivas y/o de servicios; la armonización de políticas públicas del Sector Cooperativo, y la promoción de la libertad de circulación e instalación de las cooperativas en la región» ${ }^{23}$.

Por otra parte, en el artículo 2 de esta resolución se establece que deberán participar de este desarrollo tanto entidades públicas como privadas de todos los países miembros que tengan un vínculo con las cooperativas o que sean las cooperativas en sí mismas ${ }^{24}$.

En junio de 2006, el Presidente del Comité Ejecutivo de CUDECOOP consideró que los avances del MERCOSUR respecto a la percepción de las cooperativas y su rol en la sociedad son «... el desafío de la integración, es plasmar en una institución el desafío de integrar distintas ramas del movimiento cooperativo, ramas que tienen orígenes e historias diferentes, que pertenecen a segmentos de la población también diferentes, de radicación geográfica distinta pero que, como mo-

${ }^{23}$ wWw.sitiocooperativo.com.ar

24 www.sitiocooperativo.com.ar 
vimiento único que se reconoce, piensa siempre en formas de cooperación entre sí y sobre todo de servicio a la sociedad» ${ }^{25}$.

Pero más allá de esta reunión del MERCOSUR y de lo que la misma establece, Uruguay ya ha estrechado sus vínculos cooperativos con otros países. Estos vínculos están naturalmente relacionados con los sectores en los que Uruguay ya tiene cooperativas.

Un ejemplo de ello son las relaciones entre cooperativas agrícolas uruguayas y holandesas. En el marco del proyecto que las Cooperativas Agrarias Federadas del Uruguay (CAF) está llevando adelante, se celebraron reuniones con Agriterra (Organismo de cooperación de las Organizaciones de Productores de Holanda), con el fin de identificar áreas para la cooperación horizontal entre ambas cooperativas. Los temas que se tratan para que pueda desarrollarse una intercooperatividad exitosa dependen de: la coordinación entre cooperativas primarias, la forma de financiamiento y capitalización, la modernización de la gestión de las cooperativas, las estrategias de fidelización de los socios, el rol de la organización nacional de cooperativas y las estrategias de relacionamiento con los organismos gubernamentales del país, así como la incidencia de los productores en el ámbito de los procesos de integración regionales ${ }^{26}$.

A su vez, el 29 de julio de 2005 se llevó a cabo el «1.er Encuentro Cooperativo Uruguay-Venezuela», con la finalidad de establecer acuerdos y profundizar los vínculos entre ambos países a través de la cooperación mutua, así como también fue un encuentro que abarcó las experiencias particulares entre ambos países en el área de las cooperativas.

Estos dos últimos ejemplos ponen de manifiesto el intercambio necesario que debe haber entre cooperativas de diferentes países. Para que estos intercambios sean provechosos la interculturalidad juega un rol protagónico. El motivo causal y su efecto esperable: el éxito del acuerdo dependerá probablemente del grado de comprensión, adaptación y adoctrinamiento de los valores, hábitos y costumbres de países divergentes que buscan llevar adelante esfuerzos conjuntos para el desarrollo de sus intereses.

25 www.cudecoop.org.uy
26 wWw.caf.org.uy 


\section{Los principios cooperativos y su relación con la cultura}

Los principios cooperativos que en la oportunidad se toman en cuenta son los últimos que emanan de la $\mathrm{ACl}$. Estos principios constituyen las pautas de acción de las cooperativas a nivel internacional. Los mismos son:

1. Libre adhesión y retiro voluntario de los socios.

2. Control democrático de los socios.

3. Participación económica de los socios.

4. Autonomía e independencia.

5. Fomento de la educación cooperativa, entrenamiento e información.

6. Cooperación entre cooperativas.

7. Compromiso con la comunidad.

Dentro de los principios de las cooperativas existen varios que señalan la importancia de la intercooperación y del fomento de actividades que propicien vínculos culturales entre las cooperativas, sus miembros y la sociedad. El principio 6 del cooperativismo, la «cooperación entre cooperativas: las cooperativas sirven a sus miembros más eficazmente y fortalecen el movimiento cooperativo, trabajando de manera conjunta por medio de estructuras locales, nacionales, regionales e internacionales». Bajo este principio se puede afirmar que la intención de intercooperativismo está vigente desde la definición de principios de 1966 y busca el desarrollo de acciones conjuntas entre dos o más cooperativas con el fin de optimizar la utilidad de las mismas ${ }^{27}$.

Otro principio que refiere directamente a la relación entre las cooperativas y la cultura es el número 7, que dice «La cooperativa trabaja para el desarrollo sostenible de su comunidad por medio de políticas aceptadas por sus miembros». Este principio implica el desarrollo de vínculos entre los miembros de las cooperativas y la sociedad y la búsqueda del desarrollo de acciones que mejoren y hagan perdurables dichos vínculos ${ }^{28}$.

27 CUdeCOOP (Editorial Norman) Comunidad: «Identidad y Principios Cooperativos», Ed. Comunidad del Sur (1996).

28 CUDECOOP: Cit. 
Bajo estos principios se puede decir que pese a que las cooperativas uruguayas no se caracterizan por ser principalmente culturales, sí incentivan acciones vinculadas a la sociedad y la cultura. Estas relaciones pueden y deben necesariamente intensificarse.

Sin perjuicio de lo señalado corresponde precisar que los principios cooperativos que informan las diversas leyes sectoriales que se han dictado en el país desde el año 1941 (fecha de la primera ley en la materia y relacionada en su época con el sector agropecuario del cooperativismo), responden a los principios elaborados por la $\mathrm{ACI}$ con anterioridad a la declaración de Manchestor, a la vez que ésta última informa el actual proyecto de la Ley General de Cooperativas.

Surge de lo expresado que en Uruguay las cooperativas constituyen una posibilidad cierta de desarrollo, tanto económico como intercultural, ya que con la participación conjunta entre las mismas y diversos agentes locales, pueden aprovechar las ventajas de la globalización de forma comunitaria.

Es de señalar que en fecha relativamente reciente (junio de 2006) se aprobó una ley que reguló las cooperativas sociales, que son «aquellas cooperativas de trabajo que tienen por objeto proporcionar a sus miembros un puesto de trabajo para el desarrollo de distintas actividades económicas, agropecuarias, industriales, comerciales o de servicios, con el fin de lograr la inserción social y laboral de los jefes y jefas de hogares pertenecientes a sectores con necesidades básicas insatisfechas, jóvenes, discapacitados, minorías étnicas y todo grupo en situación de extrema vulnerabilidad social».

\section{El proyecto de ley que fomenta el desarrollo cultural ${ }^{29}$}

Según el proyecto de Ley General de Cooperativas, elaborado en su origen en el ámbito de la CUDECOOP y que tiene actualmente estadio de discusión parlamentaria y cuenta con aparente voluntad política para su aprobación, sin perjuicio de la probable introducción de ciertos cambios al texto originariamente proyectado, las cooperativas tienen un gran vínculo con la cultura desde su definición: "Una coo-

29 www.cudecoop.org 
perativa es una asociación autónoma de personas que se han unido voluntariamente para hacer frente a sus necesidades y aspiraciones económicas, sociales y culturales comunes por medio de una empresa de propiedad conjunta y democráticamente controlada...» (art. 4)

Pero además, en varios artículos de la misma, se hace referencia a la relación que debe tener una cooperativa en lo que se refiere a la sociedad y su cultura, a realizarse de forma particular y/o conjunta entre cooperativas y/o federaciones. Para ello se crea un Fondo de Educación y Capacitación que tiene como fin: "...la difusión y promoción del cooperativismo, la formación de los socios y trabajadores en técnicas cooperativas, económicas y profesionales, al sostenimiento de los organismos de integración de segundo y tercer grado que cumplan funciones educativas, de asistencia técnica e investigación y, complementariamente, la atención de objetivos de incidencia social, cultural o medioambiental en el área en que la cooperativa desarrolle sus actividades (...). Dichas actividades podrán ser desarrolladas directamente por la cooperativa o con la participación de federaciones, confederaciones o entidades auxiliares especializadas (...). Integrarán el Fondo de educación y capacitación el porcentaje de los excedentes cooperativos que se asigne al mismo, el porcentaje de los excedentes derivados de la prestación de servicios a terceros que disponga el Estatuto, el cual no podrá ser inferior al veinte por ciento y las donaciones y las ayudas recibidas de terceros con ese destino específico...» (art. 76)

Adicionalmente, se hace referencia a las cooperativas culturales, las cuales deben tener como objeto «... perseguir el interés general de la comunidad mediante la promoción y la plena integración social o laboral de personas y grupos a través de:

a) La prestación de servicios sociales relacionados con la educación, asistencia, trabajo, sanidad, cultura y recreación, dirigidas a la protección de la infancia, la adolescencia y la juventud, a los adultos mayores, las personas con minusvalía y otros grupos desfavorecidos.

b) El desarrollo de distintas actividades económicas, agropecuarias, industriales, comerciales o de servicios, dirigidas a la inserción laboral de los jóvenes y mujeres, minorías étnicas, exreclusos, alcohólicos, toxicómanos y personas marginadas que sufran cualquier clase de exclusión social...» (art. 191) 
Se advierte cierta, parcial similitud de redacción entre los términos arriba transcriptos y los propios de la definición legal de las llamadas «cooperativas sociales» y en cuanto se refiere a los sujetos beneficiarios o alcanzados por esta última normativa, entre otros justamente: «jóvenes, discapacitados, minorías étnicas y todo grupo en situación de extrema vulnerabilidad social».

\section{Perspectivas de futuro}

Entendemos necesario promover y perfeccionar modelos de intercooperación que estimulen un crecimiento ordenado y sostenible, que busque y procure un aumento y fortalecimiento de las relaciones entre las cooperativas desde el punto de vista del fin primario (prestación de servicios a sus asociados) y del desarrollo de políticas orientadas a la unificación y aceptación de diversas corrientes culturales.

Con un objetivo común de las cooperativas, que es el de desarrollar actividades que presten un servicio para los miembros de las mismas acorde a sus necesidades sociales y económicas, y coherente con el respectivo objeto o actividad socio-estatutaria o contractual, aquellas desarrollan y/o pueden desarrollar acciones que permitan el desenvolvimiento del intercooperativismo y del pluriculturalismo, constituyéndolas así en agentes de socialización que colaboren con el desarrollo de sociedades que acepten sin mayores rispideces y con toda naturalidad, fluidez y armonía la diversidad cultural, que estrechen los lazos interculturales a través de objetivos comunes también definidos en común, que permitan asimismo superar ciertas asimetrías, todo lo cual también podría contribuir a soluciones de mayor equidad, en todos los campos del quehacer humano.

Las cooperativas son parte de los medios teóricos y prácticos que ayudan a la socialización y la formación del individuo y contribuyen a las pautas de comportamiento a nivel social. Por ende la relación entre las cooperativas y la cultura ya existe en la realidad material, viviente de la sociedad pero podrían afianzarse y fortalecerse a través de ciertos factores claves como son, entre otros:

a) Identidad. Las cooperativas pasan a ser formadores de identidad, ya que ello permite abordar procesos de selección de 
estrategias y objetivos, establecer relaciones con su entorno y definir las pautas de comportamiento entre sus miembros y de estos con el entorno.

b) Socialización. Aprovechar que las cooperativas son agentes del proceso de socialización, por lo que podrían educar a los individuos hacia una promoción de la pluriculturalidad y del intercooperativismo, como componentes de las reglas de juego por ser parte integrante de una cooperativa.

Entonces se podría asegurar que más allá de que las cooperativas tienen un fin primario de servicio las mismas podrán, más aún, deberían promover la cultura ya que cuentan para tal efecto con ventajas claves como serían las siguientes:

— Entendiéndose por tal, no necesariamente que su causa fin es la obtención de ganancias y la distribución de utilidades entre sus asociados al estilo de las sociedades civiles y comerciales (ya que tal causa fin en las cooperativas, una vez más, es la prestación de servicios a sus afiliados), sino que ofrecen ventajas o beneficios económicos y sociales de ciertos contenidos o efectos cuantitativos-cualitativos de significación.

- Considerándose que todo emprendimiento cooperativo depende de que sus miembros tengan plena conciencia, desde el inicio, de que son parte de una sociedad globalizada que busca la integración y el interrelacionamiento con otras cooperativas, tanto a nivel local como nacional y/o internacional.

- Teniéndose la certeza de que colectivamente podrían alcanzar objetivos que serían un avance tanto a nivel económico como de producción y que parte de estos objetivos serían el fomento de la multiculturalidad y de la aceptación de todo tipo de individuos que persigan igual fin.

Por lo tanto las cooperativas son un medio relevante que puede ofrecer a los socios la capacidad de desarrollarse económicamente pero también social y culturalmente.

Por otra parte. Se está viviendo una era de digitalización que conlleva un uso de Internet cada vez mayor, no sólo por el alcance del mismo sino por los largos períodos de tiempo que los usuarios navegan por la red. Esto lleva a una consecuencia expresada por Manuel Castells: "La mayor parte de los movimientos sociales y políticos del 
mundo de todas las tendencias utilizan Internet como forma privilegiada de acción y organización», y frente a esta situación dicho autor considera que «los movimientos sociales de nuestra sociedad se desarrollan cada vez más, en torno a códigos culturales, a valores. Hay movimientos reivindicativos tradicionales, pero los movimientos más importantes -medioambiente, ecologismo, mujeres, derechos humanos-son movimientos de valores» ${ }^{30}$.

Frente a esta situación las cooperativas pueden, más aún, deben ser parte de un mundo global que interactúa. Las cooperativas pueden lograr acuerdos interculturales con otras cooperativas (ya sea de otra localidad y/o rubro) que signifiquen un posicionamiento internacional referente a sus valores y objetivos y que le permitan desarrollarse económica, cultural y socialmente en diferentes segmentos de mercado.

Las cooperativas, bajo este concepto, pueden ser medios para lograr lo que Sergio Vilar expresa como: "una conciencia planetaria solidaria» ${ }^{31}$, donde se promocione una cultura general con subculturas, y donde las cooperativas como organizaciones sin fines de lucro sino de servicio, puedan seguir extendiéndose y ampliándose como una fuente propicia de trabajo, cooperativismo y cultura que tenga normativas de desarrollo cada vez más accesibles y ágiles en el siglo XXI.

En suma: todas las cooperativas pueden ser culturales (aunque sea un segundo objetivo) y fomentar el interculturalismo. Las cooperativas son un medio de interacción que tiene la ventaja de tener asociados que si bien buscan un incentivo económico pueden propiciar justamente, como parte y contribución a la identidad cooperativa, también la integración cultural. Este es también el reto, y la oportunidad, de las cooperativas uruguayas.

\section{Bibliografía}

AsunCIÓN-LANDE, Nobleza C.: «Comunicación Intercultural», ed. McGraw-Hill, 1988, Argentina.

30 CAStells, Manuel: Revista Letra Internacional, núm. 71 (2001), pp. 12 y 13.

31 VILAR, Sergio: «El futuro de la Cultura», pp. 233. Ed. Plaza \& Janes (1998), España. 
Bertullo, Jorge: "Cooperativismo en Uruguay», Comité For The Promotion, and Advancement Of Cooperatives (COPAC-FAO). Abril de 1993, Uruguay.

CASTELLS, Manuel: «Letra Internacional», artículo La sociedad red, verano de 2001, España.

CUDECOOP (Editorial Norman) COMUnidad: «Identidad y Principios Cooperativos», Ed. Comunidad del Sur, 1996.

CUDECOOP, «Propuestas programáticas del Movimiento Cooperativo Uruguayo». Noviembre de 1998.

CUDECOOP: «Catálogo del Cooperativismo Uruguayo», ed. GEGA, 1993.

ERRANDOneA, Alfredo; Supervielle, Marcos: «Las Cooperativas en el Uruguay. Análisis Sociológico del Primer Relevamiento Nacional de Entidades Cooperativas», ed. FCU (1992).

Huntingron, Samuel P.; HARRISON, Lawrence E.: «La cultura es lo que importa», ed. Planeta (2001), Argentina.

Mederos, Jorge, «Los Nuevos Desafíos. El cooperativismo y la globalización», ed. CEDECOOP/Centro Cooperativo Sueco, 1998.

RIPPE, Siegbert: «Régimen legal de las Sociedades Cooperativas en el Derecho Uruguayo», 2. ${ }^{a}$ edición, ed. Fundación de Cultura Uruguaya (1976), Uruguay.

RIPPE, Siegbert «Los problemas Jurídicos de las Cooperativas», ed. FCU, Serie Cooperativismo y Sociedad, Uruguay (1987).

SARLO, Beatriz: "Escenas de la vida Posmoderna», ed. Ariel, X edición (1998), Argentina.

TerRA, Juan Pablo: «Proceso y significado del Cooperativismo uruguayo», ed. Arca/ Banda Oriental (1986), Uruguay.

TOURAINE, Alan: «Crítica a la modernidad», ed. Fondo de Cultura Económica Argentina (1992).

VILAR, Sergio: «El futuro de la Cultura», ed. Plaza \& Janes (1998), España.

\section{Sitios en Internet}

www.blues.uab.es

www.cidob.ec

www.caf.org.uy

www. cudecoop.org

www.neticoop.org

www.minci.gov.ve

www.aulaintercultural.org

www. unircoop.org

www.sitiocooperativo.com.ar

www.caf.org.uy

www.stephweb.com 